\title{
The Analysis of Driver's Recognition Time of Different Traffic Sign Combinations on Urban Roads via Driving Simulation
}

\author{
Kun Liu $(\mathbb{D})$ and Hongxing Deng $(\mathbb{D}$ \\ School of Traffic and Transportation, Northeast Forestry University, Harbin 150040, China \\ Correspondence should be addressed to Hongxing Deng; 1969dhx@nefu.edu.cn
}

Received 12 April 2021; Revised 20 June 2021; Accepted 4 July 2021; Published 12 August 2021

Academic Editor: Xinqiang Chen

Copyright (C) 2021 Kun Liu and Hongxing Deng. This is an open access article distributed under the Creative Commons Attribution License, which permits unrestricted use, distribution, and reproduction in any medium, provided the original work is properly cited.

\begin{abstract}
Given the impact of traffic sign combinations (TSC) on the driver's visual recognition, this paper analyzed the influence on the driver's visual recognition process. It used the cognitive psychology theory to establish the information transmission model during the traffic sign combinations. It abstracted the information transmission model to construct the driver's information processing model. Simultaneously, according to the analysis of the traffic sign combinations of the urban roads, this paper carried out the driver's visual recognition simulation test when the traffic signs were combined, measured the reaction time of the driver's visual recognition of multiple combinations of traffic signs, and analyzed the driver's recognition time (DRT) range in the traffic sign combinations. It used correlation analysis, robust estimation, polynomial regression, and other methods to obtain a significant relationship between the driver's recognition times in different traffic sign combinations (DTSC). Then it built polynomial regression analysis models, fitted the data, and visualized the fitting results. The results show that through the analysis of the experimental data, based on ensuring certain accuracy, the driver's recognition time of the traffic sign combinations of the urban road increased appropriately. There is a significant relationship between different traffic sign combinations and the driver's recognition time. As the number of traffic signs increases, the driver's recognition time increases significantly. Besides, under certain conditions, gender, age, and the driving experience will impact the driver's recognition time during the traffic sign combinations. The research results can provide the relevant theoretical basis for the setting of urban traffic signs, provide a powerful reference for the revision of various traffic sign setting standards and norms, and provide ideas for future research on the sign system.
\end{abstract}

\section{Introduction}

In recent years, with the rapid development of the economy, urbanization has gradually accelerated. As an indispensable part of the urban road network, traffic signs play an important role, especially in the accuracy of traffic information transmission, the direction of traffic conditions, and the timeliness of traffic regulations. Therefore, to maximize the effect of urban traffic signs, many experts and scholars have done a lot of research work and achieved some fruitful research results.

In terms of regulations and standards, the "Manual on Uniform Traffic Control Devices" [1] in the United States improves traffic regulations and categorizes them according to the traveler's destination. Depending on the characteristics of different urban areas, the layout design and information display of traffic signs are emphasized. To meet the daily travel needs of residents to the greatest extent, the maximum number of conventions to the destination is marked as the desired point. And with the rapid development of the urban transport network, the quality of service is improving. Japan's "Road Marking Manual" [2] on constructing urban road signs has unified provisions. It includes the production of signs, placement, etc. and has standardized regulations. Simultaneously, when the driver travels at night, different materials have different degrees of luminescence, and the success rate of the driver's mark information on different materials is also different. China's "Road Traffic Signs and Markings" [3] and "Code for Layout of Urban Road Traffic Signs and Markings" [4] set out the basic 
principles and color, shape, pattern, and set requirements of the signs. They classified the traffic signs and specified the design, manufacture, setting, and construction requirements of traffic signs. They are based on long-term traffic management experience and the current situation of road traffic development and absorbing the new standards of road traffic signs so that road traffic signs are more complete, eyecatching, and scientific. Besides, there is the European "Convention on Road Signs and Signals" and Canada's "Manual of Traffic Signs and Markings."

In academic research, Dutta et al. [5] studied that when the message is presented within a relatively short time and repeated twice, the driver can obtain more information. Edquist et al. [6] studied that billboards can change the driver's visual attention mode, and the time for drivers to recognize road signs will increase. Rogé et al. [7] studied that, with the increase of driver's age and speed, the simulation extends the driving task time, and the driver's driving field of view will worsen. Filtness et al. [8] studied that if roads' complexity increases, the number of road signs will increase accordingly, and research shows that setting multiple traffic signs on the same signpost can solve insufficient traffic signs in narrow road areas. Vilchez [9] analyzed traffic signs from a cognitive perspective and determined their impact on the vehicle's motion trajectory in driving simulation tasks. Liu et al. [10] analyzed the average gaze time of the driver by using the eye-moving instrument. And the results showed that the visual effect of traffic signs on the new driver was greater than the experienced driving test. Jiang et al. [11] studied the gaze time of the road sign. They found that the gaze time increased with the speed and the number of road names. Du et al. [12] conducted experiments on roadside redundancy information to interfere with the driver's visual recognition time. They found that auxiliary information and star advertising had the greatest impact on driving. Zhao et al. [13] explored the relationship between driving behavior and the location of warning signs by driving simulation tests. Zhang et al. [14] analyzed the driver's distraction recognition method and established the state recognition. Xiong et al. [15] analyzed the factors that influence driving simulation on driver alertness. From the perspective of visual function, Schnell et al. [16] studied the influence of brightness and font size on the recognition time of traffic signs and the accuracy of information transmission. The results show that larger and brighter signs can transmit information to the driver more effectively, reduce information collection time, and improve transmission accuracy. Zabihi et al. [17] proposed a test method based on the human vision principle to detect and identify traffic signs in the driver's visual field. Huang et al. [18] took the driver's factors as a research perspective and analyzed them, which have a significant impact on the driver's understanding of the sign information. According to the research results, factors such as gender, income level, and education level have significant impact. Also, drivers in different countries have different levels of understanding. Ellahyani et al. [19] proposed a new traffic guide sign detection and recognition method tested on the German traffic sign detection and recognition benchmark and the Swedish traffic sign data set and achieved good results. He and Dai [20] focused on the feature extraction of traffic guidance signs and proposed a new method that combines local and global features to identify traffic guidance signs. The research results show that the accuracy of this method reaches $97.67 \%$, which is better than the single feature method and greatly shortens the recognition time. Chao et al. [21] proposed a calculation method for special guide signs to reduce wind load measures, saving construction materials and costs. Wogalter and Barlow [22] took the driver as the research object, analyzed the social influence on the driver's psychological activities, and put forward the necessary factors for the design of traffic signs. Li et al. [23] researched results and came up with a suggestion to add straight information to the intersections' road sign. It shows that the improvement will help the driver judge the path position relationship and improve its visual recognition efficiency. Li et al. [24, 25] analyzed the desirability of the sign layout, sign setting position, the focus of significant information of the guide signs of different road positions abroad, and the application of the layout graphics and sign forms of domestic road signs, etc. Suggestions for improvement are reference significance with the design and revision of traffic signs in actual projects. Liu et al. [26] considered the visual recognition of the external environment, the sign's location, the sign's layout, and its information. They proposed ten indicators for evaluating the sign.

In summary, the existing research has made some theoretical research achievements in road sign recognition analysis, roadside traffic sign blocking, road sign layout design, and traffic direction sign setting effect evaluation [27-39]. Most of the research focuses on one traffic sign (OTS). However, in reality, there are various traffic signs. So that not only can save costs and effectively use resources but also give full play to traffic signs. Therefore, this paper analyses the information transmission system when traffic signs are combined from cognitive psychology and constructs its information transmission model. By abstracting the transmission model, the paper obtained the driver's information processing model. The model and investigation analysis carried out the driving simulation of different traffic sign combinations (DTSC). Through robust estimation, correlation analysis, polynomial regression, and other methods to process and analyze the data, the paper researches and explores the relationship between the driver's recognition time (DRT) during different traffic sign combinations (DTSC). It also discusses and analyzes other possible factors that affect the visual recognition time of traffic signs.

\section{The Mechanism of Information Transmission and Processing}

2.1. The Mechanism of Traffic Sign Information Transmission. Whether the correct identification of traffic signs to convey the information is an important guarantee of safe driving, DTSC will impact the driver's recognition process.

The driver's perception process of traffic signs can generally be divided into five stages [40]: (1) discovery, (2) recognition, (3) cognition, (4) understanding and decision- 
making, and (5) reaction and operation. The analysis of cognitive psychology shows that graphics and symbols are the carriers of information transmission. In visual recognition, the main purpose of drivers is to obtain more information conveyed by traffic signs. Therefore, it can use the communication system model to construct the information transmission model of DTSC on the urban road. The schematic diagram of the information transmission model in DTSC is shown in Figure 1.

\subsection{The Mechanism of Driver's Information Processing.} The driver's information transmission model and the cognitive psychology theory are analyzed. The process of acquiring, processing, storing, and using relevant information of traffic signs in the cognitive process is abstracted to construct an information model for the driver to handle DTSC, as shown in Figure 2. Thus, the degree of external information accepted by the driver is directly related to its ability to handle the information effectively. Traffic signs are the main body carrying information, and their visual recognition will directly affect the driver's perception of information. The DTSC conveys too much information. And it will cause a serious visual burden to the driver, thereby reducing the driver's degree of recognition and affecting the reasonableness of the sign set.

\section{Methods}

3.1. Simulation Test. In this paper, the method of indoor simulation is used to recognize signs on the road. According to the principle of ergonomics, it makes the human-computer interface, uses AutoCAD, Photoshop, and other software to draw the corresponding urban road traffic signs, makes a certain combination of traffic signs, then carries on the visual recognition process experiment to the subjects, and records the driver's various reaction times. The experiment can be divided into two stages:

(i) The preparation stage: (1) draw traffic signs, (2) debug test instruments, (3) recruit subjects, etc.

(ii) The subject's visual recognition stage: (1) give a certain combination sign, (2) perform a visual recognition process test on the subjects, (3) record various relevant data of the subjects, etc.

3.1.1. The Preparation for the Test. This paper selected a total of 20 experimental subjects by the random sampling method. Including different ages, genders, driving ages, as shown in Figure 3, corrective vision is above 1.0.

The test used a total of 15 groups of traffic signs for the experiment, which includes (1) one traffic sign (OTS), (2) two kinds of traffic sign combinations (TTSC), and (3) three kinds of traffic sign combinations (TKTSC). There were four types of signs, such as prohibition signs, warning signs, indicator signs, and guide signs. The traffic signs should be drawn by the relevant standards $[3,4]$ and did not appear to be contrary to the provisions or realistic settings of the situation. The diagram of various types of DTSC in the test is shown in Table 1.

3.1.2. The Visual Recognition Test. It used ergonomic principles to carry out the various drives' reactions data during recognize traffic signs. The schematic diagram of the flow chart is shown in Figure 4.

(1) Experimenters arranged for the subjects to sit in a designated position.

(2) They explained the rules and purpose of the experiment to subjects.

(3) They used the computer to play various pre-prepared combination traffic signs to familiarize the subjects with the process.

(4) With the formal experiment, the experimenters recorded the relevant subjects' data in turn until all the subjects were finishing the experiment.

(5) Experimenters counted the data of the various experiments.

3.2. The Robust Estimation Model. The theory of robust estimation is the application of the principle of least squares. In the inevitable case of roughness, the estimation method's selection to minimize the impact of the unknown valuation to arrive at the best estimate in normal mode is a common experimental data processing method in ergonomics application research [41]. To reduce the variability of the collected data due to system, human operation, etc., use the robust estimation theory to process and analyze the experimental data. After trial calculation comparison, use a set of indicators depending on the weighted calculation of data sample as follows:

$$
w_{i j}=\frac{1}{\left|T_{i j}-\bar{T}_{i}\right|},
$$

where $w_{i j}$ is the weight of the test data, $i$ is the number of TSC, $j$ is the subject's number, $T_{i j}$ is the recognition time of the $i$ group of the $j^{\text {th }}$ subject (s), and $\bar{T}_{i}$ is the mean recognition time of $i$ group traffic signs (s).

Calculate the weighted mean of DRT for DTSC, and calculate the formula by

$$
\widetilde{T}_{i}=\sum \frac{w_{i j} \times T_{i j}}{\sum w_{i j}},
$$

where $\widetilde{T}_{i}$ is the weighted mean recognition time of the drivers of $i$ group traffic signs (s), that is, the DRT referred to in this article.

3.3. The Polynomial Regression Model. In practical problems, the change of the dependent variable is often affected by several important factors. It is necessary to use two or more influencing factors as independent variables to explain the dependent variable's change which is called multiple regression [42]. The schematic diagram of the polynomial regression model is shown in Figure 5. 


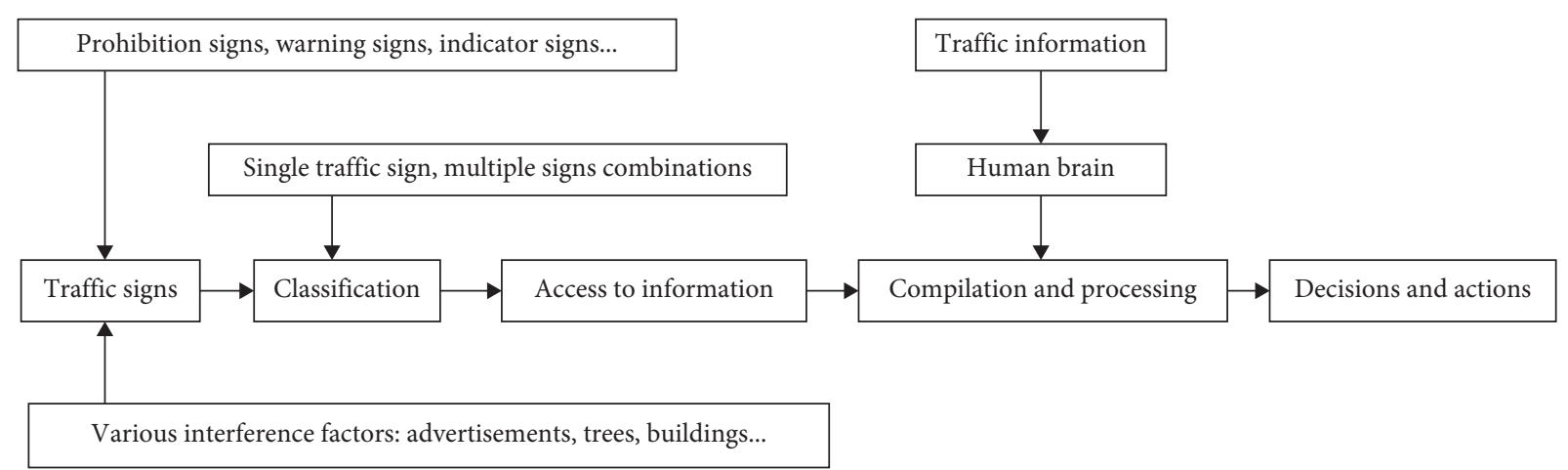

FIGURE 1: The information transmission model in DTSC.

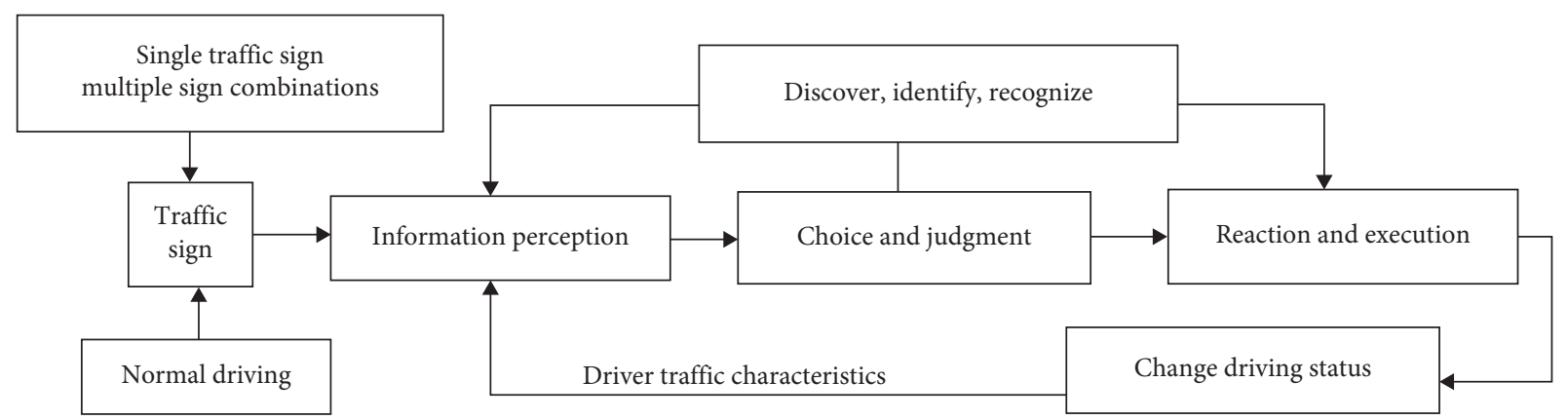

FIgURE 2: The driver's information processing model in DTSC.

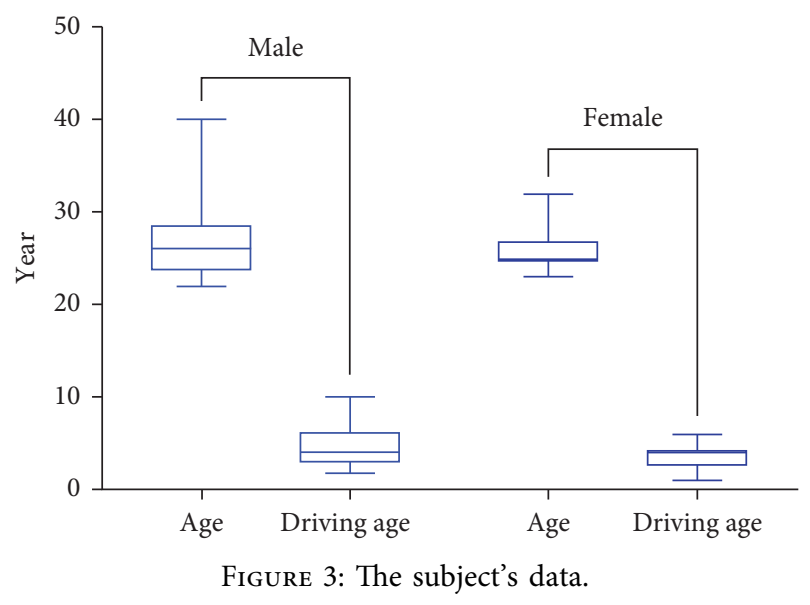

To explore the correlation between the DRT in DTSC, we established the following model:

$$
y_{i}=\beta_{0}+\beta_{1} x_{1_{i}}+\beta_{2} x_{2_{i}}+\cdots+\beta_{k} x_{k i}+e_{i},
$$

where $\beta_{0}$ is the regression constant, $\beta_{i}$ is the regression coefficient, $y_{i}$ is the DRT for OTS (s), $x_{k i}$ is the DRT during the DTSC (s), $k$ is the number of sign combinations, $i$ is the number of subjects, and $e_{i}$ is the residuals, usually assuming $e \sim N\left(0, \sigma^{2}\right)$.

The matrix expression is

$$
y=x \beta+e,
$$

TABle 1: The various types of DTSC.

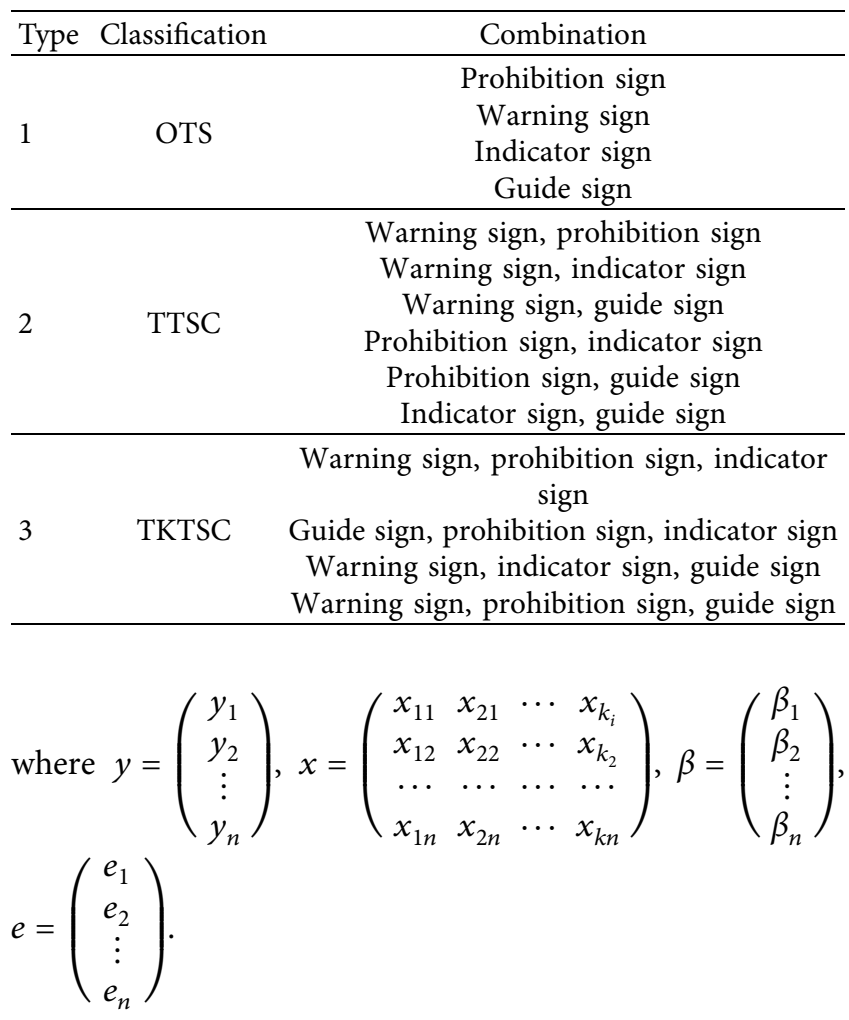

3.3.1. The Model Parameter Test. Under the normal distribution assumption, if $x$ is full rank, use the least-squares 


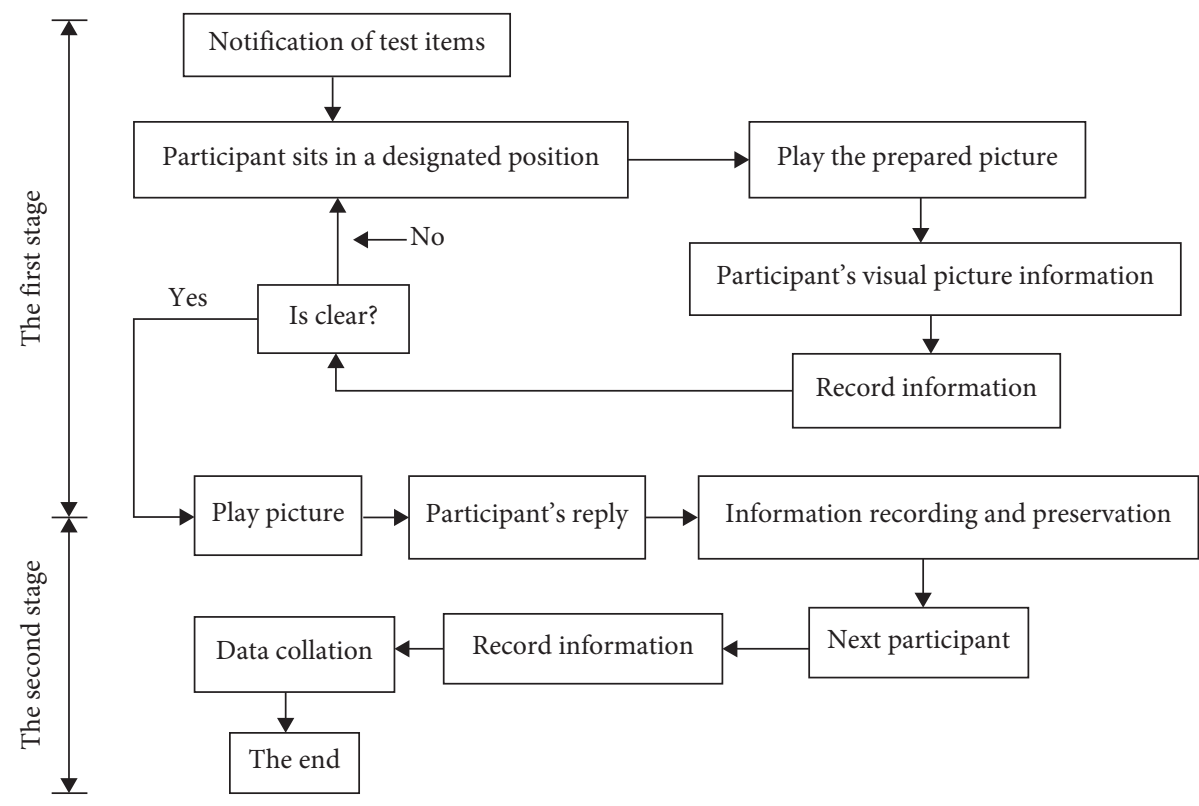

FIgURE 4: The test flow chart.

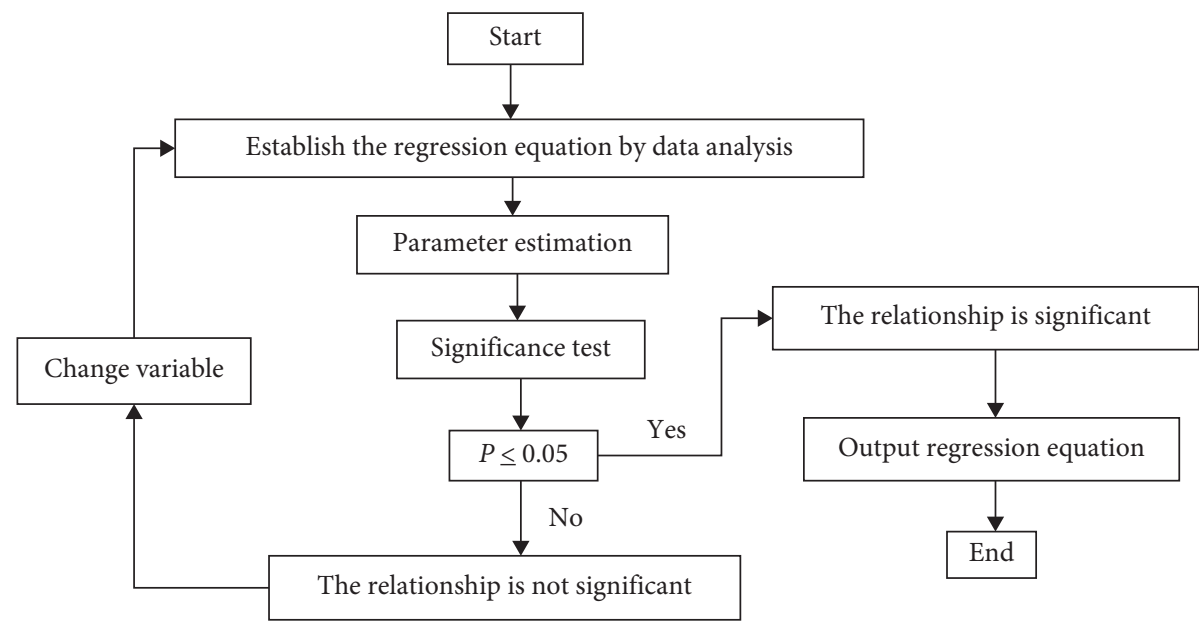

Figure 5: The polynomial regression model.

estimation result of the parameters of the regression model by $(5)-(7)$ :

$$
\begin{aligned}
& x^{T} x \widehat{\beta}=x^{T} x \widehat{\beta}+x^{T} e, \\
& \left\{\begin{array}{l}
\sum_{i} e_{i}=0, \\
\sum_{i} x_{k i} e_{i}=0,
\end{array}\right.
\end{aligned}
$$

where $\bar{\beta}$ is the estimated value of the parameter.

Thus,

$$
\left\{\begin{array}{l}
\hat{\beta}=\left(x^{T} x\right)^{-1} x^{T} y, \\
\beta_{0}=\bar{y}-\beta_{1} \bar{x}_{i}-\cdots-\beta_{k} \bar{x}_{k}, \\
e=y-x \hat{\beta} .
\end{array}\right.
$$

The estimate of random error variance is

$$
\hat{\sigma}_{\mu}^{2}=\frac{e^{T} e}{n-k-1} .
$$

The fitting of the degree of excellence test is by

$$
R^{2}=1-\left(\frac{n-1}{n-k-1}\right) \frac{\text { SSR }}{\text { SST }}
$$

where $R^{2}$ is the determinable coefficient, the range of values is $[0,1]$, it is in the total change of the factor variable, the proportion of the change is explained by the regression equation, the closer to 1 , the higher the fitting degree of the various sample data points, $\operatorname{SST}=\sum\left(y_{i}-\hat{y}\right)^{2}$ is the sum of the total deviation squares of the data, and $\operatorname{SSR}=\sum e_{i}^{2}$ is the sum of squares for regression. 
3.3.2. The Significance Test. The significance test of the regression equation is to test the significance of the entire regression equation. The calculation formula of $\mathrm{F}$ statistic is

$$
F=\left(\frac{n-k-1}{k}\right) \frac{\mathrm{SSR}}{\mathrm{SST}}
$$

where SSE $=$ SST - SSR is the sum of the residuals' squares, for a given significant level of $\alpha$; check the deny domain is $F>F_{a}(k, n-k-1)$.

The significant test of the regression coefficient is

$$
t_{i}=\frac{\beta_{i}}{\sqrt{c_{i i}\left(\sum e_{i}^{2} / n-k-1\right)}}
$$

where $c_{i i}$ is elements on the main diagonal in $\left(x^{T} x\right)^{-1}$, for a given notable level $\alpha$; check the deny domain is $\left|t_{i}\right|>t_{a / 2}(n-k-1)$.

\section{Results}

4.1. Data Acquisition. The schematic diagram of the 15 groups of DRT test results is shown in Figure 6. The schematic diagram shows that a total of 300 pieces of valid data are obtained. Among them, the maximum value of DRT is $3.14 \mathrm{~s}$, the minimum value is $0.55 \mathrm{~s}$, and the mean value is $1.64 \mathrm{~s}$. The overall data fluctuates little and is relatively stable. The schematic diagram of the test data is shown in Table 2.

Generally speaking, the DRT during visual traffic signs is in the range of 0.50 to $2.00 \mathrm{~s}$. However, since this experiment mainly involves the DTSC, the DRT should be increased appropriately. According to the test data analysis, the relationship between DRT and accuracy rate in DTSC is shown in Figure 7.

It shows from Figure 7 that the accuracy rate in the test data increases with the DRT. The curvature is larger within $2.8 \mathrm{~s}$, and the growth rate is accelerated. Over $2.8 \mathrm{~s}$, the curvature increases, the speed is flat, and the accuracy rate does not change much. Therefore, it is more appropriate for the DRT in the range of 0.55 to $2.80 \mathrm{~s}$ during the DTSC for visual recognition, and its accuracy rate is $98.3 \%$.

It used (1)-(2) to make a robust estimate of the data to obtain the weighted mean DRT. Statistical analysis of the data shows that the DRT in the three tests does not change much. The maximum values of DRT for the three groups are $0.925 \mathrm{~s}, 0.986 \mathrm{~s}$, and $1.177 \mathrm{~s}$. The minimum values are $2.087 \mathrm{~s}$, $2.094 \mathrm{~s}$, and $2.323 \mathrm{~s}$, and the mean values are $1.587 \mathrm{~s}, 1.557 \mathrm{~s}$, and $1.701 \mathrm{~s}$. The mean DRT difference is less than $0.15 \mathrm{~s}$. However, the test is affected by the system or human error, so the mean DRT of TTSC is smaller than OTS. But by comparison, it found that the mean DRT difference is less than $0.05 \mathrm{~s}$, and its impact is small. When the number of traffic signs increases to three, the DRT increases significantly. The schematic diagram of the descriptive statistics is shown in Figure 8.

4.2. The Data Analysis. To further understand the relationship between DRT of DTSC, do a scatter plot diagram of it, as shown in Figure 9. It shows a linear relationship between DRT of OTS, TTSC, and TKTSC.

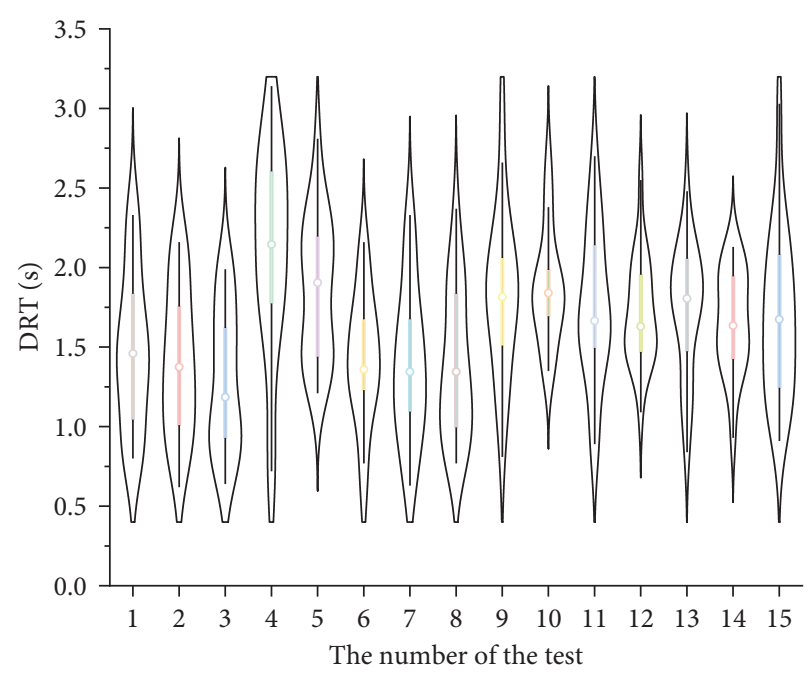

Figure 6: The violin plot of test data in DTSC.

TABLE 2: The statistics of DRT in DTSC.

\begin{tabular}{lccc}
\hline Number & Maximum (s) & Minimum (s) & Mean (s) \\
\hline 300 & 3.14 & 0.55 & 1.64 \\
\hline
\end{tabular}

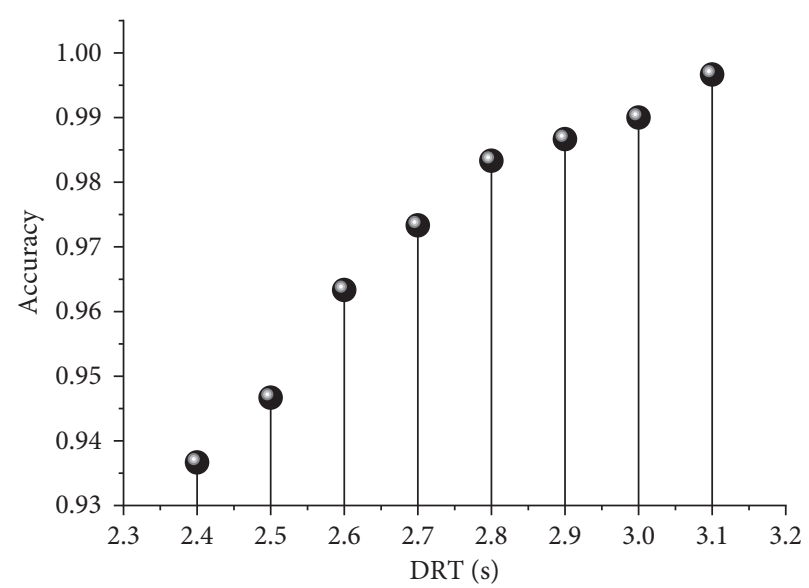

FIgURE 7: The relationship between the DRT and the accuracy rate.

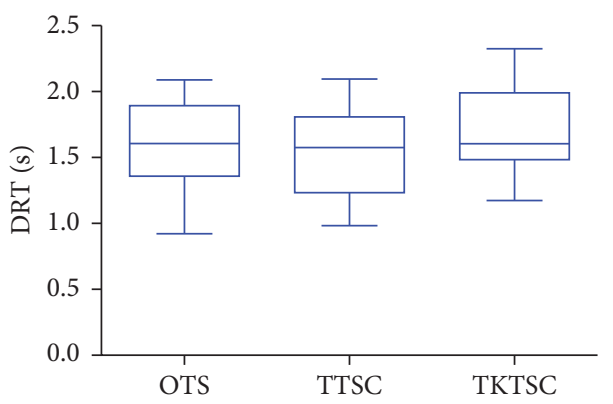

FIgURE 8: The descriptive statistics of DRT in DTSC.

Therefore, through correlation analysis, it is good to measure the degree of correlation between variable factors. The schematic diagram of the relevance analysis is shown in 


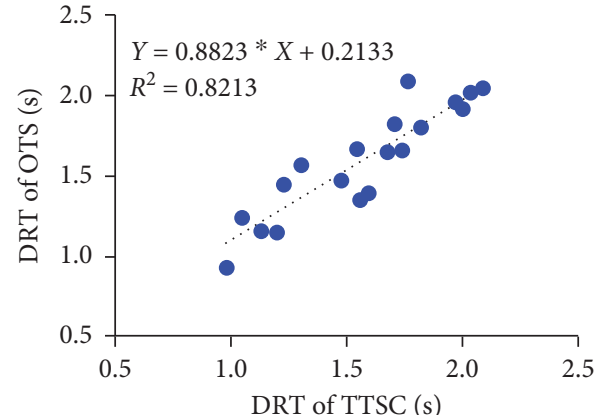

(a)

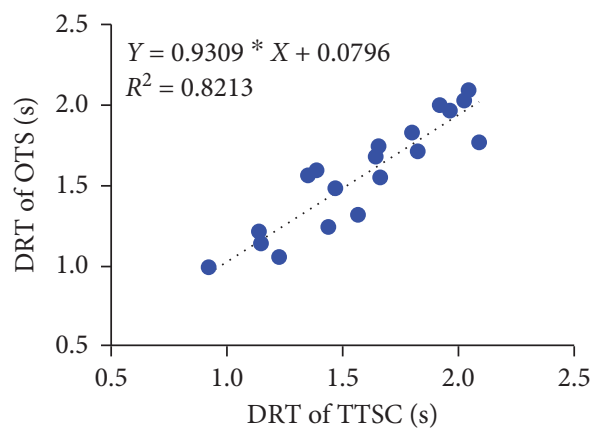

(c)

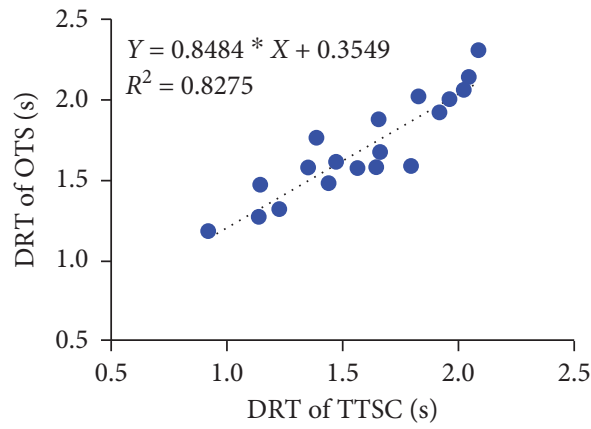

(e)

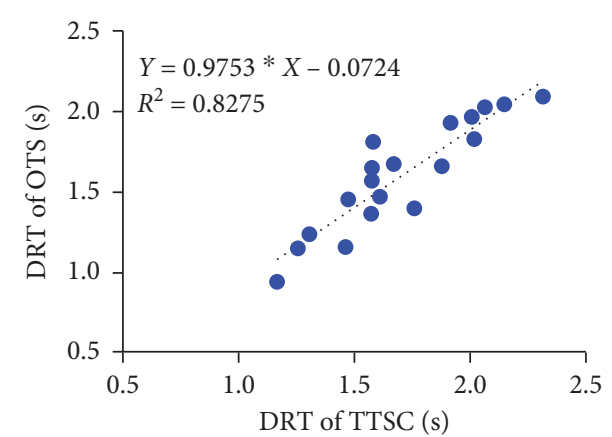

(b)

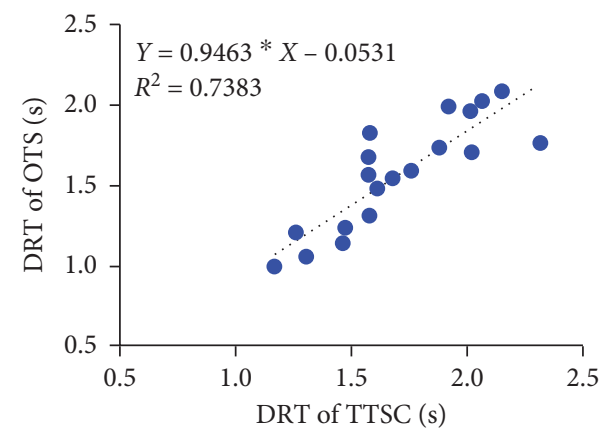

(d)

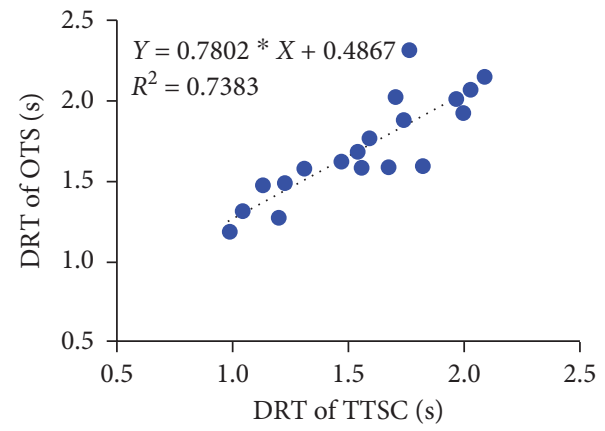

(f)

FIgure 9: The scatter plot of DRT in DTSC.

Figure 10. It shows that the correlation coefficients between the DRT of OTS, DRT of TTSC, and the DRT of TKTSC are 0.906 and 0.910 , respectively. And the correlation between the three is significant when the confidence level is 0.01 .

The experimental data are analyzed by the polynomial regression method. It shows that the data sample is independent, there is no collinearity, and the residuals conform to the normal distribution. The schematic diagram of the relevant coefficient test results is shown in Table 3 , the data is fitting, and the regression equation is

$$
s_{1}=0.464 s_{2}+0.536 s_{3}-0.048,
$$

where $s_{1}$ is the DRT of OTS (s), $s_{2}$ is the DRT of TTSC (s), and $s_{3}$ is the DRT of TKTSC (s).

Therefore, we can find that $R^{2}=0.874$, which shows that the regression model fits well. The significance coefficient of $s_{2}$ is

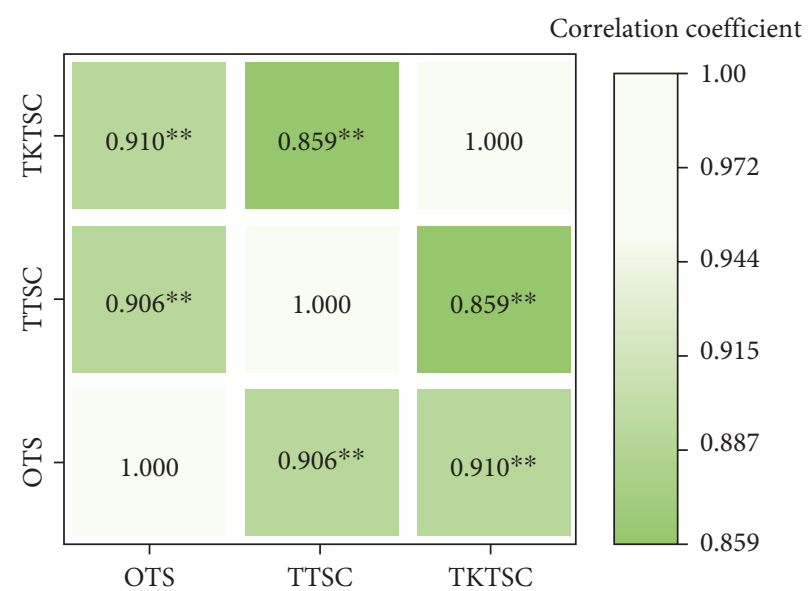

FIgURE 10: The relevance analysis of DRT in DTSC. 
TABLE 3: The relevant coefficient test results.

\begin{tabular}{|c|c|c|c|c|}
\hline Model & $\mathrm{B}$ & $T$ & Sig. & VIF \\
\hline (Constant) & -0.048 & -0.315 & 0.756 & \\
\hline$s_{2}$ & 0.464 & 2.987 & 0.008 & 3.822 \\
\hline$s_{3}$ & 0.536 & 3.137 & 0.006 & 3.822 \\
\hline$R^{2}$ & & & 0.874 & \\
\hline $\mathrm{F}$ & & & 66.624 & \\
\hline$P$ & & & $<0.01$ & \\
\hline
\end{tabular}

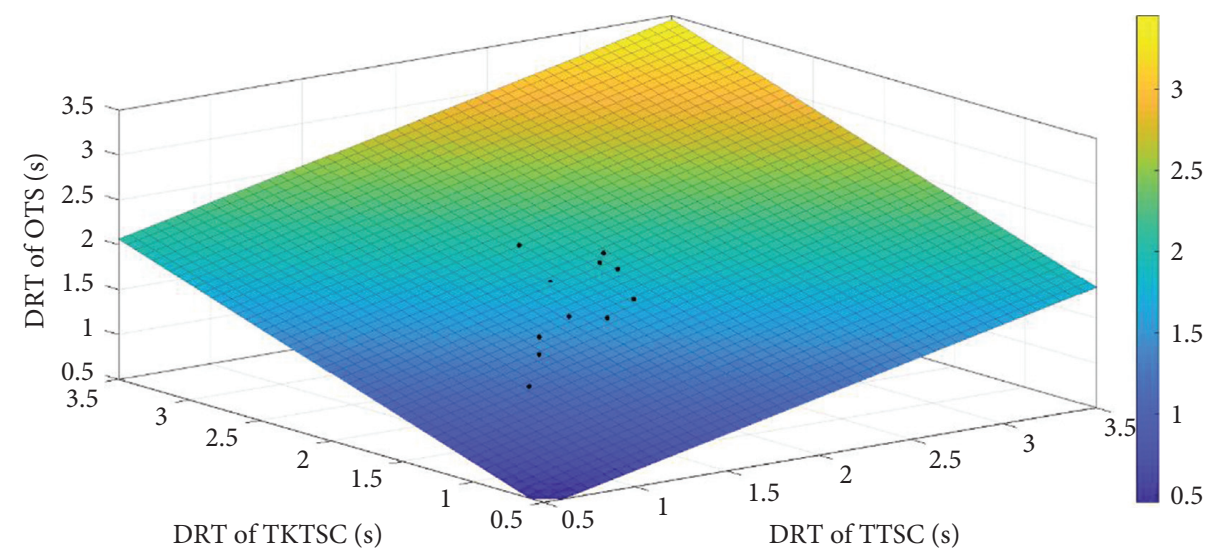

FIgURE 11: The visualization of the results.

TABle 4: The statistical description of factors.

\begin{tabular}{|c|c|c|c|c|c|c|}
\hline & & $\mathrm{N}$ & Mean & Std. deviation & Minimum & Maximum \\
\hline \multirow{3}{*}{ Age (year) } & Male & 10 & 27.1 & 5.087 & 22 & 40 \\
\hline & Female & 10 & 25.9 & 2.644 & 23 & 32 \\
\hline & Total & 20 & 26.5 & 3.993 & 22 & 40 \\
\hline \multirow{3}{*}{ Driving experience (year) } & Male & 10 & 4.8 & 2.348 & 2 & 10 \\
\hline & Female & 10 & 3.6 & 1.430 & 1 & 6 \\
\hline & Total & 20 & 4.2 & 1.989 & 1 & 10 \\
\hline \multirow{3}{*}{ MDRT (s) } & Male & 10 & 1.652 & 0.354 & 1.030 & 2.100 \\
\hline & Female & 10 & 1.579 & 0.291 & 1.200 & 2.060 \\
\hline & Total & 20 & 1.616 & 0.318 & 1.030 & 2.100 \\
\hline \multirow{3}{*}{ DRT of TTSC (s) } & Male & 10 & 1.598 & 0.478 & 0.860 & 2.330 \\
\hline & Female & 10 & 1.177 & 0.412 & 0.630 & 1.890 \\
\hline & Total & 20 & 1.388 & 0.485 & 0.630 & 2.330 \\
\hline \multirow{3}{*}{ DRT of TKTSC (s) } & Male & 10 & 1.792 & 0.328 & 1.220 & 2.130 \\
\hline & Female & 10 & 1.675 & 0.489 & 0.840 & 2.480 \\
\hline & Total & 20 & 1.734 & 0.410 & 0.840 & 2.480 \\
\hline
\end{tabular}

0.008 , and the significance coefficient of $s_{3}$ is 0.006 . It shows that $s_{2}$ and $s_{3}$ can significantly affect $s_{1}$. Since the coefficient of $s_{2}$ is 0.464 and the coefficient of $s_{3}$ is 0.536 , it reflects $s_{2}$ and $s_{3}$ can positively affect $s_{1}$. That is, as the number of traffic signs increases, the DRT increases significantly. The schematic diagram of the visualization of the results is shown in Figure 11.

4.3. The Analysis of Other Influencing Factors. During visual recognition, many factors affect the DRT to traffic signs. Therefore, other influencing factors that affect the DRT are further analyzed. The statistical description of factors is shown in Table 4. In the Table, MDRT is the mean value of DRT in 15 groups.

Through the correlation analysis of the experimental data, the experimental data is explored in depth. It shows that the correlation coefficients between gender, age, driving experience, and MDRT are $-0.154,-0.309$, and -0.120 . It shows that the relationship between gender, age, driving experience, and MDRT is not significant. The schematic diagram of the relevance analysis is shown in Figure 12.

(1) In Figure 12, the test data of the TTSC shows that the correlation coefficient between the DRT and gender 


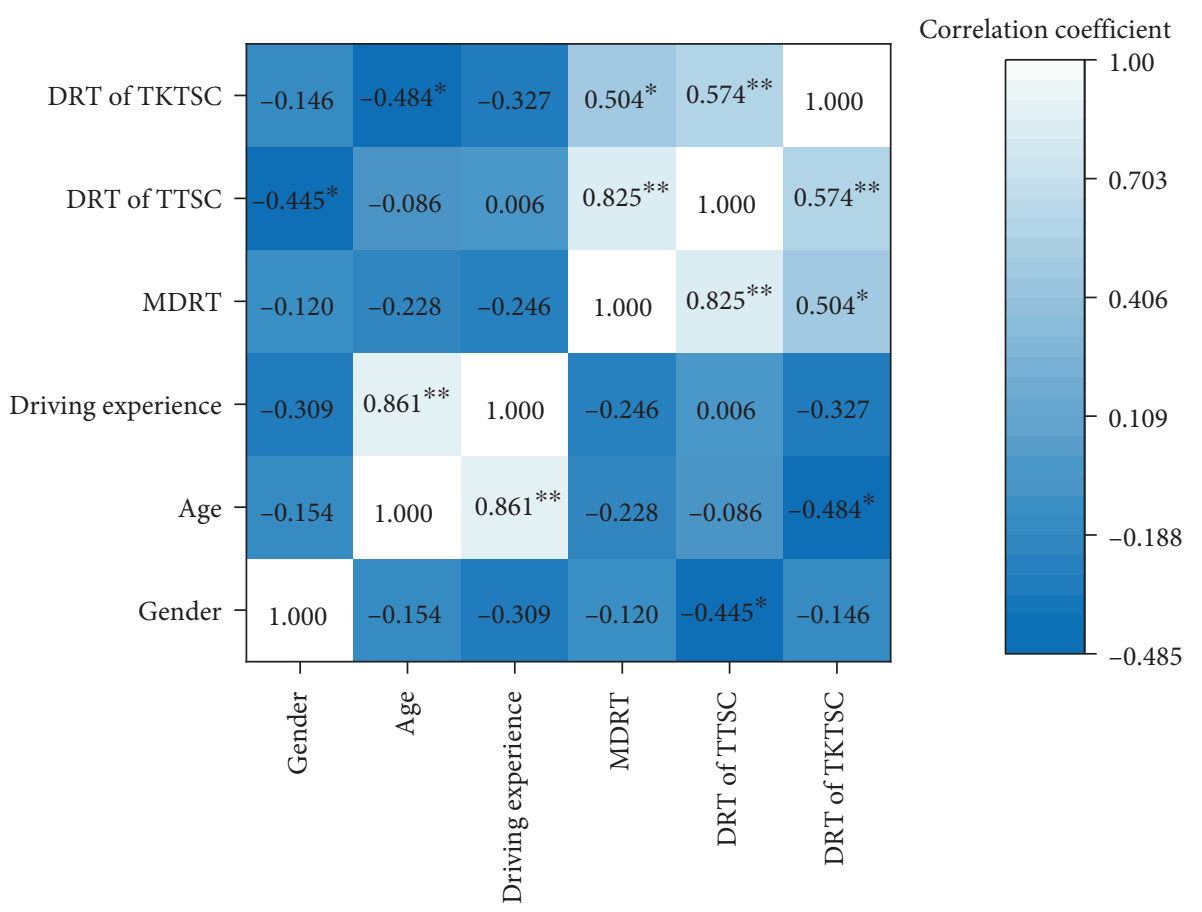

FIgURE 12: The relevance analysis between other factors.

is -0.445 . When the confidence level is 0.05 , the correlation between the two is significant. The test shows that $P=0.049<0.05$, the mean DRT of boys is $1.598 \mathrm{~s}$, and the mean DRT of girls is $1.177 \mathrm{~s}$. The mean DRT of boys is slightly longer than that of girls, reflecting that girls can recognize traffic signs faster than boys.

(2) In addition, with the experimental data of the TKTSC, the correlation coefficient between the DRT and age is -0.484 . When the confidence level is 0.05 , the correlation between the two is significant. At the same time, there is a certain negative correlation between age and DRT. As the age increases, the DRT gradually decreases, and the traffic signs will be seen more quickly.

(3) The relationship between driving experience and the DRT is not significant. From Figure 12, the correlation coefficient between age and driving experience is 0.861 . When the confidence level is 0.01 , the correlation between the two is significant. There is a certain positive correlation. As the age increases, the driving experience also increases, reflecting that the driving experience can also affect the driver's visibility. As the age increases, the driving experience increases, and the DRT is reducing. That is, experienced drivers can recognize traffic signs faster than novice drivers.

\section{Conclusion}

In this paper, the DRT is tested and analyzed by simulation method with the DTSC on the city road. Correlation analysis is used to study the relationship between DRT during DTSC. Other factors affecting DRT are discussed. Through the analysis of the experimental data, the following conclusions can be drawn.

Generally speaking, the DRT during visual traffic signs is in the range of 0.50 to $2.00 \mathrm{~s}$. However, it involves the DTSC, and the DRT should be increased appropriately. According to the analysis of the test data, the DRT is in the range of 0.55 to $2.80 \mathrm{~s}$ during the DTSC, and its accuracy rate is $98.3 \%$.

The number of DTSC will have a certain impact on DRT, and the correlation between OTS and TSC is significant. That is, as the number of traffic signs increases, the DRT will increase. The experimental data shows that there is no significant relationship between gender, age, driving experience, and MDRT. Under certain conditions, gender, age, and driving experience impact the DRT during DTSC by analyzing the original test results, meaning that boys had slightly higher response times than girls. As age and driving experience increase, the DRT decreases. Experienced drivers react faster than novice drivers.

The article used indoor simulation experiments to study the driver's recognition time of different sign combinations. The results can improve the actual traffic operation and reduce the risk of accidents caused by traffic sign problems, which can make roads more open. At the same time, they provide the relevant theoretical basis for the setting of urban traffic signs, provide a powerful reference for the revision of various traffic sign setting standards and norms, and provide ideas for future research on the sign system. But due to its use of the driving simulation test method in this experiment, it is influenced by the sample size, human error, and other factors affecting the analysis results. However, it carries out the weighted mean calculation to reduce the difference. But the DRT in recognition is affected by various factors, such as individual differences, physiological and psychological 
factors, information volume, setting mode, and other factors. They will impact the driver's visual recognition. The follow-up needs to be further studied.

\section{Data Availability}

The data used to support the findings of this study are available from the corresponding author upon request.

\section{Conflicts of Interest}

The authors declare that they have no conflicts of interest.

\section{Authors' Contributions}

K.L. and H.D. conceptualized the study; K.L. and H.D. developed the methodology; K.L. provided the software; H.D. carried out validation; K.L. performed formal analysis; data curation was carried out by K.L. and H.D.; original draft was as for written by K.L.; K.L. and H.D. reviewed and edited the article. All the authors have read and agreed to the published version of the manuscript.

\section{Acknowledgments}

This research was supported by the Fundamental Research Funds for the Central Universities of China (No. 2572017AB27) and the National Natural Science Foundation of China (No. 71771047).

\section{References}

[1] H. Al-Madani and A.-R. Al-Janahi, “Assessment of drivers' comprehension of traffic signs based on their traffic, personal and social characteristics," Transportation Research Part F: Traffic Psychology and Behaviour, vol. 5, no. 1, pp. 63-76, 2002.

[2] S. Guha, R. Rastogi, and K. Shim, "CURE: an efficient clustering algorithm for large databases," Information Systems, vol. 26, no. 1, pp. 35-58, 1998.

[3] General Administration of Quality Supervision, Inspection and Quarantine of the People's Republic of China, "GB 57682009, Road Traffic Signs and Markings," Standards Press of China, Beijing, China, 2009.

[4] Ministry of Housing and Urban-Rural Development of the People's Republic of China, GB 51038-2015, Code for layout of urban road traffic signs and markings, China Planning Press, Beijing, China, 2015.

[5] A. Dutta, D. L. Fisher, D. A. Noyce, Use of a driving simulator to evaluate and optimize factors affecting understandability of variable message signs," Transportation Research Part F: Traffic Psychology and Behaviour, vol. 7, no. 7, pp. 209-227, 2004.

[6] J. Edquist, T. Horberry, S. Hosking, and I. Johnston, "Effects of advertising billboards during simulated driving," Applied Ergonomics, vol. 42, no. 4, pp. 619-626, 2011.

[7] J. Rogé, T. Pébayle, E. Lambilliotte, F. Spitzenstetter, D. Giselbrecht, and A. Muzet, "Influence of age, speed and duration of monotonous driving task in traffic on the driver's useful visual field," Vision Research, vol. 44, no. 23, pp. 2737-2744, 2004.

[8] A. J. Filtness, G. Larue, A. Schramm et al., "Safety implications of co-locating road signs: a driving simulator investigation," Transportation Research Part F: Traffic Psychology and Behaviour, vol. 47, pp. 187-198, 2017.
[9] J. L. Vilchez, "Representativity and univocity of traffic signs and their effect on trajectory movement in a driving-simulation task: regulatory signs," Journal of Safety Research, vol. 66, pp. 101-111, 2018.

[10] A. Liu, K. Liao, Y. Xia et al., "The influence factors of the traffic signs visibility," Road Traffic and Safety, vol. 16, pp. 33-37, 2016.

[11] J. Jiang, J. Lu, and Y. Li, "Setting of road guide sign based on driver's recognition characteristics," Journal of Southeast University (Natural Science Edition), vol. 40, pp. 1089-1092, 2010.

[12] Z. Du, H. Wan, Z. Zheng et al., "Experiment of visual interference test of urban roadside redundant information to guide sign," Journal of Highway and Transportation Research and Development, vol. 31, pp. 119-124, 2014.

[13] X. Zhao, W. Guan, L. Huang et al., "Research on influence of warning sign position in sharp curve on driving behavior," Journal of Highway and Transportation Research and Development, vol. 31, pp. 101-107, 2014.

[14] H. Zhang, D. Qian, C. Shao et al., "Driver's distraction states identification simulating driving environment," China Journal of Highway and Transport, vol. 31, pp. 43-51, 2018.

[15] J. Xiong, L. Yuan, and D. Xiong, "Influencing factors of driver vigilance based on simulation experiment," Journal of Chongqing Jiaotong University (Natural Sciences Edition), vol. 37, pp. 82-89, 2018.

[16] T. Schnell, L. Yekhshatyan, and R. Daiker, "Effect of luminance and text size on information acquisition time from traffic signs," Transportation Research Record: Journal of the Transportation Research Board, vol. 2122, no. 1, pp. 52-62, 2009.

[17] S. J. Zabihi, S. M. Zabihi, S. S. Beauchemin, and M. A. Bauer, "Detection and recognition of traffic signs inside the attentional visual field of drivers," in Proceedings of the 2017 IEEE Intelligent Vehicles Symposium, pp. 583-588, Los Angeles, CA, USA, June 2017.

[18] K. Huang, X. Chen, and J. Tang, "Research on utmost information in guide signs based on $3 \mathrm{D}$ virtual simulation and evaluation system," in Proceedings of the 2010 2nd International Conference on Multimedia and Computational Intelligence (ICMCI 2010), Wuhan, China, 2010.

[19] A. Ellahyani, M. E. Ansari, and I. E. Jaafari, "Traffic sign detection and recognition based on random forests," Applied Soft Computing, vol. 46, pp. 805-815, 2016.

[20] X. He and B. Dai, "A new traffic signs classification approach based on local and global features extraction," in Proceedings of the 2016 6th International Conference on Information Communication and Management (ICICM), pp. 121-125, Hatfield, UK, October 2016.

[21] S. Chao, C. W. Jiao, and S. Liu, "Research on feasibility of computational fluid dynamics (CFD) method for traffic signs board calculation," in Proceedings of the IOP conference series: Earth and Environmental Science2016 International Conference on New Energy and Future Energy System (NEFES 2016), vol. 40, p. 12061, Beijing, China, August 2016.

[22] M. S. Wogalter and T. Barlow, "Injury severity and likelihood in warnings," Proceedings of the Human Factors Society Annual Meeting, vol. 34, no. 8, pp. 580-583, 1990.

[23] G. Li, P. Shi, and K. Zhang, "Study on drivers' cognitive performance of urban road guide sign layout," China Safety Science Journal, vol. 26, no. 8, pp. 100-104, 2016.

[24] W. Li, M. Jiang, and Z. Tang, "Study on the improvement of highway guide sign system," Journal of Highway and 
Transportation Research and Development, vol. 24, no. 12, pp. 117-143, 2007.

[25] W. Li, H. Chen, and G. Zhang, "Study on guide signs for indirect highway," Journal of Highway and Transportation Research and Development, vol. 24, no. 7, pp. 121-126, 2007.

[26] F. Liu, M. Huang, J. Zheng et al., "Study on evaluation system of guide signs based on dual strategy," Journal of Highway and Transportation Research and Development, vol. 34, no. 2, pp. 106-122, 2017.

[27] K. Liu, H. Deng, and Y. Pei, "Probability and improvement measures of dynamic failure of urban trunk road overhead traffic signs," Academic Journal of Manufacturing Engineering, vol. 18, no. 3, pp. 176-184, 2020.

[28] M. Costa, A. Simone, V. Vignali, C. Lantieri, and N. Palena, "Fixation distance and fixation duration to vertical road signs," Applied Ergonomics, vol. 69, pp. 48-57, 2018.

[29] S. Bortei-Doku, S. Kaplan, C. G. Prato, and O. A. Nielsen, "Road signage comprehension and overload: the role of driving style and need for closure," Transportation Research Procedia, vol. 24, pp. 442-449, 2017.

[30] N. Byshov, A. Simdiankin, and I. Uspensky, "Method of traffic safety enhancement with use of RFID technologies and its implementation," Transportation Research Procedia, vol. 20, pp. 107-111, 2017.

[31] J. R. Bañares, S. A. Caballes, M. J. Serdan, A. T. Liggayu, and M. F. Bongo, "A comprehension-based ergonomic redesign of Philippine road warning signs," International Journal of Industrial Ergonomics, vol. 65, pp. 17-25, 2018.

[32] S. Zhao, The Layout Information Threshold and Density of Traffic Signs on Urban Arterials, Southwest Jiaotong University, Chengdu, China, 2018.

[33] W. Su, Research on Inform Signs of Grade Intersection Based on Driver's Visual Characteristics, People's Public Security University of China, Beijing, China, 2019.

[34] X. Chen, X. Xu, Y. Yang, H. Wu, J. Tang, and J. Zhao, "Augmented ship tracking under occlusion conditions from maritime surveillance videos," IEEE Access, vol. 8, pp. 42884-42897, 2020.

[35] Z. Zhu, T. Guo, and S. Pan, "A placement distance model for advance guide signs to expressway exits," Transport Research, vol. 4, pp. 44-50, 2018.

[36] Y. Zu, Y. Li, Y. Wang et al., "An approach to limit value of information amount for urban guide signs," Journal of Transport Information and Safety, vol. 30, pp. 38-42, 2012.

[37] X. Chen, S. Wu, C. Shi et al., "Sensing data supported traffic flow prediction via denoising schemes and ANN: a comparison," IEEE Sensors Journal, vol. 20, no. 23, pp. 14317-14328, 2020.

[38] F. Dai, "Design and analysis of logo layout topology structure in traffic sign information management system," Digital Technology \& Application, vol. 37, no. 5, pp. 177-179, 2019.

[39] H. Jiang and H. Deng, "Traffic incident detection method based on factor analysis and weighted random forest," IEEE Access, vol. 8, pp. 168394-168404, 2020.

[40] X. Xiao, X. Zhao, and J. Zhang, "Research on design and location of auxiliary deceleration lane traffic signs," Automobile Applied Technology, pp. 64-67, 2017.

[41] L. Guo and J. Yang, "Analysis and application of robust estimation based on IGG III weight function," Mine Surveying, vol. 4, pp. 64-67+105, 2019.

[42] J. Guo, "Multiple linear regression prediction model of automobile fuel consumption based on the existence of interaction terms," Guangxi Quality Supervision Guide Periodical, vol. 11, pp. 138-140, 2019. 